\title{
Kinetic insights on wet peroxide oxidation of caffeine using EDTA-functionalized low-cost catalysts prepared from compost generated in municipal solid waste treatment facilities
}

\author{
Jose L. Diaz de Tuesta ${ }^{a, *}$, Flávio V.M. de Almeida ${ }^{a, b}$, Jessica R.P. Oliveira ${ }^{a, c}$, \\ Paulo Praça ${ }^{\mathrm{d}}$, Mário C. Guerreiro ${ }^{\mathrm{b}}$, Helder T. Gomes ${ }^{\mathrm{a}}$ \\ ${ }^{a}$ Centro de Investigação de Montanha (CIMO), Instituto Politécnico de Bragança, Campus de Santa \\ Apolónia, 5300-253 Bragança, Portugal \\ ${ }^{\mathrm{b}}$ Departamento de Química, Universidade Federal de Lavras, Campus Universitário, 37200-000, Lavras/MG, Brazil \\ ${ }^{\mathrm{c}}$ Universidade Tecnológica Federal do Paraná (UTFPR), Campus de Ponta Grossa, Av. Monteiro Lobato s/n- km 4, 84016-210, Ponta \\ Grossa PR, Brazil \\ ${ }^{\mathrm{d}}$ Resíduos do Nordeste, EIM, S.A. Empresa Intermunicipal, Mirandela, 5370-340, Portugal
}

\section{A R T I C L E I N F O}

\section{Article history:}

Received 27 January 2021

Received in revised form 17 June 2021

Accepted 19 September 2021

Available online 23 September 2021

\section{Keywords:}

Circular economy

Waste valorization

Compost

Catalytic wet peroxide oxidation

Contaminants of emerging concern

Micropollutant

\begin{abstract}
A B S T R A C T
Nowadays, sorted organic fraction of municipal solid waste is typically treated by anaerobic digestion processes, resulting therein a solid stream, further processed to obtain compost, whose production is higher than the existing demand as fertilizer. The current work proposes an alternative strategy for the recovering of compost through the production of low-cost catalysts by calcination $(1073 \mathrm{~K})$ and sulfuric acid treatments, followed by sequential functionalization with tetraethyl orthosilicate (TEOS) and ethylenediamine tetraacetic acid (EDTA). Activity and stability of the catalysts are assessed in the wet peroxide oxidation of synthetic wastewater effluents contaminated with caffeine, a model micro-pollutant, achieving its complete removal after $6 \mathrm{~h}$ at 353$383 \mathrm{~K}$ and catalyst loads of $0.5-2.5 \mathrm{~g} \mathrm{~L}^{-1}$. The increase of the catalytic activity of the materials upon functionalization with TEOS and EDTA is demonstrated and a kinetic modeling of caffeine degradation and hydrogen peroxide consumption with the best catalyst is assessed by pseudo-first power-law rate equations.
\end{abstract}

(C) 2021 Elsevier B.V. All rights reserved.

\section{Introduction}

Nowadays, waste management through mechanical biological treatment (MBT) systems consists in the use of the organic fraction separated from undifferentiated municipal solid waste (MSW) to feed anaerobic digestion processes, resulting therein a biogas and a solid stream, further processed to compost. In 2018, the amount of municipal solid waste used for composting in the EU-27 reached 37 million tonnes (16.9\% of MSW generated per capita) (Eurostat, 2021). The compost produced is used as fertilizer, but the available amount largely exceeds the demand required for agriculture applications and it is accumulated on landfill sites (Diaz de Tuesta et al., 2020a).

\footnotetext{
* Corresponding author.

E-mail address: jl.diazdetuesta@ipb.pt (J.L. Diaz de Tuesta).
} 
Nowadays, the use of low-cost sources, such as biomass (Diaz de Tuesta et al., 2021; Juhola et al., 2019), sludge (Wang et al., 2020), metal slags (Cheng et al., 2017), furnace ashes (Ramirez et al., 2019), to produce catalysts, has become popular. Wastes are inexpensive and the process allows converting the undesirable waste into value-added materials and catalysts. In recent works, our group developed methods to produce successfully catalysts from matured compost obtained from mechanical biological treatment plants of municipal solid waste. One of the methods considered the preparation of hydrochars by hydrothermal carbonization upon 1-5 h under different operating conditions (423-503 $\mathrm{K}$ and compost:water $=30-130 \mathrm{~g} \mathrm{~L}^{-1}$ ), optimizing the catalytic performance of hydrochars in the decomposition of hydrogen peroxide (Roman et al., 2021). Another approach considered the recovery of compost by activation and thermal treatments at $673-1023 \mathrm{~K}$ to prepare active catalysts for the treatment of oily wastewater and for the removal of lipophilic substances by catalytic wet peroxide oxidation (CWPO) (Diaz de Tuesta et al., 2020a).

CWPO is a promising advanced oxidation technology running at moderate operating conditions $(\mathrm{T}=298-403 \mathrm{~K}, \mathrm{P}=1-$ 5 bar) that allows to degrade organic pollutants in water bodies through the action of hydroxyl and hydroperoxyl radicals produced from the decomposition of hydrogen peroxide over an appropriate catalyst. The technology shows a great potential for the degradation of many micro-pollutants (e.g. pharmaceuticals, personal care products, steroid hormones, among other emerging compounds) (Van et al., 2020), as previously demonstrated (Huaccallo-Aguilar et al., 2021; Santos Silva et al., 2019). Among those compounds, caffeine has gained increased attention, due to its consumption in beverages, dietary supplements and medications, and to its persistence in aquatic environment, since caffeine degradation through biodegradation and/or photolysis is poor (Keerthanan et al., 2020; Paiga et al., 2019; Richardson and Kimura, 2017; Korekar et al., 2020). For these reasons, increasing efforts have been devoted to the removal of caffeine by several techniques, such as adsorption (Alvarez-Torrellas et al., 2016; Álvarez et al., 2015; Álvarez Torrellas et al., 2015), filtration (Ojajuni et al., 2016), biological treatments (Chtourou et al., 2018; Froehner et al., 2010) and advanced oxidation processes, as for example Fenton (Oliveira et al., 2014), photocatalysis (Elhalil et al., 2018, 2017) and photo-Fenton (Klamerth et al., 2010; Trovo et al., 2013). However, CWPO has been scarcely studied in the removal of caffeine, in spite of showing great potential for the removal of other micro-pollutants (Huaccallo et al., 2019; Mirzaei et al., 2017; Munoz et al., 2017; Santos Silva et al., 2019).

Aiming to increase catalytic performance in CWPO, modification of catalytic materials have been widely explored by functionalization (Ribeiro et al., 2013) and doping with heteroatoms (Diaz de Tuesta et al., 2020b; Martin-Martínez et al., 2016) and metals, mainly iron (Anis and Haydar, 2018; Motuzas et al., 2018). These strategies introduces additional electron donating abilities to the materials, improving its efficiency for the decomposition of hydrogen peroxide into hydroxyl radicals (Zhu et al., 2019). In this sense, ethylenediamine tetraacetic acid (EDTA) has been widely explored as electron donor in photocatalytic processes to enhance the electron transfer or charge-transfer at the catalyst surface of these systems (Kim and Choi, 2010; Mori et al., 2012; Pastrana-Martínez et al., 2013). In Fenton-like systems, EDTA has been studied as chelating agent for ferric ions (Fe-EDTA complex) to increase the degradation of organic contaminants at neutral pH (Lu et al., 2010; Messele et al., 2019; Tachiev et al., 2000). However, the efficiency of EDTA to promote the electron transfer and to improve the performance of heterogeneous catalysts in CWPO has not yet been explored.

The present work aims to evaluate the catalytic activity of EDTA functionalized materials prepared from matured compost generated in mechanical biological treatment plants of municipal solid waste for wet peroxide oxidation of caffeine, used as model micro-pollutant. The catalytic activity and stability of the EDTA-functionalized catalyst is explored at different operating conditions of temperature and catalyst loads and a suitable kinetic model is proposed for the CWPO of caffeine at those conditions.

\section{Materials and methods}

This section contains: (1) the reagents used for the materials preparation and CWPO experiments; (2) the methods followed in the preparation of the catalysts; (3) analytical techniques used for their characterization; (4) methods applied to assess their catalytic activity in the CWPO of caffeine; and (5) the mathematical development followed for the kinetic modeling in the CWPO of caffeine with the catalysts prepared.

\subsection{Reagents}

The matured compost was supplied by a waste management company (Resíduos do Nordeste, EIM), as obtained after anaerobic digestion and composting of the organic fraction of MSW. It is rich in several metals, such as $\mathrm{Si}(8.2 \%)$, Ca (4.9\%), $\mathrm{Fe}(1 \%), \mathrm{K}(1 \%), \mathrm{Mg}(0.8 \%), \mathrm{Na}(0.6 \%)$ among other in less percentage ( $\mathrm{Cd}, \mathrm{Cr}, \mathrm{Cu}, \mathrm{Hg}, \mathrm{Ni}, \mathrm{Pb}, \mathrm{Zn}, \mathrm{Ti}<0.1 \%)$ (wet basis moisture of 29.6\%) (additional characterization of the compost is summarized in previous works (Diaz de Tuesta et al., 2020a; Roman et al., 2021)). For the preparation of the materials, sulfuric acid (96-98 wt\%), tetraethyl orthosilicate (TEOS, $98 \mathrm{wt} \%$ ), EDTA ( $\geq 99 \%$ ), absolute ethanol (99.8 wt\%) and ammonium hydroxide (ammonia solution $25 \mathrm{wt} . \%$ ), obtained from from Riedel-de-Haën, Fluka, Labkem, Fisher Chemical and Panreac, respectively, were used. Nitrogen gas (99.9995\%) from Linde was used for calcination. The reactants involved in the CWPO runs were caffeine ( $>99 \%$ ) and hydrogen peroxide $(30 \%, w / v)$, provided by VWR chemicals and Fluka, respectively. Titanium (IV) oxysulfate (15 wt\% in dilute sulfuric acid 99.99\%) and sodium sulfite (98 wt\%), used in analytical methods, were purchased from Sigma-Aldrich. The mobile phase used in chromatography analyses was composed of acetonitrile (99.99\%) and a solution of orthophosphoric acid $\left(\mathrm{H}_{3} \mathrm{PO}_{4}\right.$ 
85\%) available from Fisher Chemical. The reagents used for the digestion and atomic absorption spectroscopy of samples were: $\mathrm{HNO}_{3}(65 \%)$ and $\mathrm{CuCl}_{2} \cdot 2 \mathrm{H}_{2} \mathrm{O}$ supplied from Fisher Chemical; $\mathrm{HCl}(37 \%), \mathrm{CaCO}_{3}(99.9 \%), \mathrm{NaCl}(98 \%), \mathrm{Al}\left(\mathrm{NO}_{3}\right)_{3} \cdot 9 \mathrm{H}_{2} \mathrm{O}$ (98.8\%), $\mathrm{FeCl}_{2} \cdot 4 \mathrm{H}_{2} \mathrm{O}$ (98\%) obtained from VWR chemicals; and $\mathrm{SrCl}_{2} \cdot 6 \mathrm{H}_{2} \mathrm{O}(99 \%) \mathrm{KNO}_{3}(>99 \%)$, and $\mathrm{Mg}\left(\mathrm{NO}_{3}\right)_{2} \cdot 6 \mathrm{H}_{2} \mathrm{O}(98 \%)$ were purchased from Acros Organics, Panreac and Sigma-Aldrich), respectively. All reagents were used as received from suppliers.

\subsection{Preparation of catalysts}

The matured compost was first washed with water to remove suspended solids, dried overnight at $378 \mathrm{~K}$ and sieved to obtain a particle size ranging from 53 to $106 \mu \mathrm{m}$ (no grinding was needed), resulting in sample CC. The resultant material was pyrolyzed under nitrogen atmosphere at $1073 \mathrm{~K}$ for $4 \mathrm{~h}$, resulting in a pyrochar (sample PC). Then, the washed compost (CC) and PC were treated with $\mathrm{H}_{2} \mathrm{SO}_{4} 5 \mathrm{M}$ at $353 \mathrm{~K}$ during $3 \mathrm{~h}$, resulting in samples C-SA and PC-SA, respectively. In addition, the functionalization of PC-SA with TEOS and EDTA was also explored, adapting the methodology described elsewhere (Lv et al., 2018). Briefly, $0.5 \mathrm{~g}( \pm 0.1 \mathrm{mg}$ ) of PC-SA was suspended in $150 \mathrm{~mL}( \pm 1 \mathrm{~mL})$ of absolute ethanol and $25 \mathrm{~mL}( \pm 1 \mathrm{~mL})$ of distilled water and dispersed in ultrasounds during $15 \mathrm{~min}$. Then $3 \mathrm{~mL}$ of $\mathrm{NH}_{3} 25 \%$ and $2.5 \mathrm{~mL}( \pm 1 \mu \mathrm{L})$ of TEOS were added at $303 \mathrm{~K}$, the resulting mixture kept under stirring. After $45 \mathrm{~min}, 0.05 \mathrm{~g}( \pm 0.1 \mathrm{mg})$ of EDTA was added and the suspension was stirred at $303 \mathrm{~K}$ for $4 \mathrm{~h}$. Afterwards, the solid was centrifuged at $6000 \mathrm{rpm}$ and thoroughly washed with distilled water until neutrality of the waters $(\mathrm{pH}$ and TOC values equal to those of the distilled water). Finally, the samples were dried overnight in oven at $333 \mathrm{~K}$, resulting in the functionalized char, sample PC-SA-TE.

\subsection{Characterization techniques}

The CHNS-elemental composition of the materials was quantified employing a Carlo Erba Instrument EA 1108 Elemental Analyzer. For determination of the ash content, $0.2 \mathrm{~g}( \pm 0.1 \mathrm{mg})$ of sample was calcined in a muffle furnace at $873 \mathrm{~K}$ for $4 \mathrm{~h}$. Then, the sample was cooled down until room temperature inside a desiccator and the mass was measured (the process was repeated until constant mass was obtained and in triplicate for each sample). Selected metals (iron, copper, sodium, calcium, magnesium, and aluminum) were quantified by digesting catalysts with $\mathrm{HNO}_{3} / \mathrm{HCl}$ during 24 $\mathrm{h}$ at $473 \mathrm{~K}$ and subsequent analysis by atomic absorption spectroscopy Varian SpectrAA 220 as described in a previous work (Cardoso et al., 2019). Iron, copper, aluminum, calcium and magnesium were analyzed using a selected lamp and using strontium chloride (for $\mathrm{Ca}$ and $\mathrm{Mg}$ determination) and nitrate potassium (for $\mathrm{Na}$ and Al quantification) to avoid interferences among the metals. CHNS-elemental analysis, ashes determination, catalyst digestion and atomic absorption spectroscopy were done in triplicate.

Fourier Transform Infrared (FT-IR) spectroscopy was performed with a Perkin Elmer FT-IR spectrophotometer UATR Two with a resolution of $1 \mathrm{~cm}^{-1}$ and scan range of 4000 to $500 \mathrm{~cm}^{-1}$ using the sample in powder solid state without further preparation. The acidity and basicity of the materials were determined following the methodology described in previous works (Roman et al., 2021; Santos Silva et al., 2019).

$\mathrm{N}_{2}$ adsorption was studied at $77 \mathrm{~K}$ using a Quantachrome NOVA TOUCH LX4 analyzer. Samples were degasified at 473 $\mathrm{K}$ under vacuum during $16 \mathrm{~h}$. The BET specific surface area $\left(S_{B E T}\right)$ was calculated by the method of Brunauer, Emmett and Teller.

\subsection{CWPO of caffeine}

The experiments were carried out in a stoppered $1 \mathrm{~L}$ glass batch reactor (Parr Instruments 5100 reactor) equipped with stirring and temperature controllers. The reactor was loaded with $400 \mathrm{~mL}( \pm 5 \mathrm{~mL})$ of caffeine aqueous solution with a concentration of $100 \mu \mathrm{g} \mathrm{mL}^{-1}$, considered as a model wastewater containing pharmaceutical compounds. The solution was adjusted to the initial $\mathrm{pH}\left(\mathrm{pH}_{0}\right)$ of $3.00( \pm 0.01)$, using $\mathrm{H}_{2} \mathrm{SO}_{4} 1 \mathrm{M}$, and heated until the pre-selected temperature (323-383 K). Upon stabilization of the temperature, $\mathrm{H}_{2} \mathrm{O}_{2}$ was added in the adequate stoichiometric dosage needed for the theoretical mineralization of caffeine $\left(C_{\mathrm{H}_{2} \mathrm{O}_{2}, 0}=508 \mu \mathrm{g} \mathrm{mL}-1\right.$ if the maximal oxidation state is considered: $\mathrm{C}_{8} \mathrm{H}_{10} \mathrm{~N}_{4} \mathrm{O}_{2}+$ $\left.29 \mathrm{H}_{2} \mathrm{O}_{2} \rightarrow 8 \mathrm{CO}_{2}+34 \mathrm{H}_{2} \mathrm{O}+2 \mathrm{~N}_{2} \mathrm{O}_{5}\right)$. Finally, the selected quantity of catalyst $\left(0.125-2.5 \mathrm{~g} \mathrm{~L}^{-1} \pm 0.1 \mathrm{mg} \mathrm{L}^{-1}\right)$ was loaded and different samples were taken from the reactor for further analysis during $24 \mathrm{~h}$. The catalyst was immediately separated by centrifugation and $\mathrm{Na}_{2} \mathrm{SO}_{3}$ was added into the aliquots taken for caffeine determination in order to consume $\mathrm{H}_{2} \mathrm{O}_{2}$. The concentration of caffeine was analyzed in duplicate with a Jasco high performance liquid chromatography system at the wavelength of $277 \mathrm{~nm}$ (UV-2075 Plus detector) with a Nucleosil 100-5 C18 column, using as mobile phase $0.65 \mathrm{~mL} \mathrm{~min}^{-1}$ (PU-2089 Plus) of an $\mathrm{A}: \mathrm{B}(10: 90)$ mixture of acetonitrile $(\mathrm{A})$ and $\mathrm{H}_{3} \mathrm{PO}_{4}(\mathrm{pH}=3)$ aqueous solution $(\mathrm{B}) . \mathrm{H}_{2} \mathrm{O}_{2}$ concentration was determined by colorimetry using $\mathrm{TiOSO}_{4}$ and a T70 spectrometer (PG Instruments Ltd.) at $405 \mathrm{~nm}$, as described in previous works (Santos Silva et al., 2019). The calibration curves $\left(\mathrm{R}^{2} \geq 0.998\right)$ were obtained using ten standard solutions.

Total Organic Carbon (TOC) was determined by Shimadzu Equipment TOC L CSH/CSN. Leached metals were quantified in triplicate only for the last sample taken from the reaction media, by atomic absorption spectroscopy (Varian SpectrAA 220), followed the method described previously. 


\subsection{Kinetic modeling}

The kinetic study of the oxidation was carried out following the methodology considered in a previous work (Quintanilla et al., 2019). The disappearance rate of each specie $i\left(-r_{i}\right.$, in $\left.\mathrm{mmol} \mathrm{h}^{-1} \mathrm{~g}^{-1}\right)$ inside the batch-reactor was expressed considering constant volume as given in Eq. (1).

$$
-r_{i}=\frac{1}{W_{\text {catal. }}} \cdot \frac{d N_{i}}{d t}=\frac{1}{C_{\text {catal. }}} \cdot \frac{d C_{i}}{d t}
$$

where $N_{i}$ and $W_{\text {catal. }}$ are the moles of compound $i$ (mmol) and the catalyst load $(\mathrm{g})$ in the reactor, respectively; $C_{i}$ and $C_{\text {catal. }}$ are the concentrations of compound $i(\mathrm{mM})$ and catalyst $\left(\mathrm{g} \mathrm{L}^{-1}\right)$, respectively; and $t$ is the time of reaction $(\mathrm{h})$.

A preliminary kinetic analysis was performed by curve-fitting method, i.e., the linear regression of the pseudo-first order power-law rate equations for the disappearance of caffeine and of hydrogen peroxide to determine the apparent kinetic constant $\left(k^{\prime}\right)$ according to Eqs. (2) and (3).

$$
\begin{aligned}
\ln \left(\frac{C_{\text {Caffeine }}}{C_{\text {Caffeine }, 0}}\right) & =-k_{\text {Caf. }}^{\prime} \cdot t \\
\ln \left(\frac{C_{\mathrm{H}_{2} \mathrm{O}_{2}}}{C_{\mathrm{H}_{2} \mathrm{O}_{2}, 0}}\right) & =-k_{\mathrm{H}_{2} \mathrm{O}_{2}}^{\prime} \cdot t
\end{aligned}
$$

Then, the rate equations proposed in this work were solved using direct-computation methods (analytical methods) minimizing the sum of squared errors $\left(S S E_{\text {model }}\right)$ of the relative concentration of each compound $i\left(r c_{i}=C_{i} / C_{i, 0}\right)$ between the experimental (exp) and the predicted (model) values, as given in Eq. (4).

$$
S S E_{\text {model }}=\sum_{n=1}^{N}\left(r c_{\text {expi, } n}-r c_{\text {modeli }, n}\right)^{2}
$$

Dimensionless $r c_{i}$ was used to take into account the differences in the order of magnitude of the concentrations among the compounds considered $\left(C_{\text {caffeine }}=0-0.515 \mathrm{mM}\right.$ and $C_{\mathrm{H}_{2} \mathrm{O}_{2}}=0-14.9 \mathrm{mM}$, whereas $C_{i} / C_{i, 0}=0-1$ for each compound $i$ ) (Diaz de Tuesta et al., 2020b).

\section{Results and discussion}

The results found by the methods described previously are presented and discussed in the following sections related to: (1) characterization of the catalyst prepared from compost; (2) their application in the CWPO of caffeine; (3) the performance of a selected catalyst at different operating conditions; and (4) the development of a kinetic model for the CWPO of caffeine.

\subsection{Characterization of catalysts}

After removing suspended solids, washing and homogenize the mature compost, it was observed a wide distribution of particle sizes $(35.8 \%, 8.3 \%, 11 \%, 40.1 \%$ and $4.8 \%$ for particle size ranges of $>250 \mu \mathrm{m}, 250-160 \mu \mathrm{m}, 160-106 \mu \mathrm{m}, 106-53$ $\mu \mathrm{m}$ and $<53 \mu \mathrm{m}$, respectively). As the resultant material show a high percentage (40.1\%) of small particles sizes ranging from 53 to $106 \mu \mathrm{m}$, it was sieved in that range resulting in sample CC (not significant changes of particle size were observed in the successive treatments to produce PC-SA and PC-SA-TE).

Table 1 summarizes the mass loss and the CHNS-elemental composition of each sample. The mass losses were estimated between the mature compost and each sample. The washing and homogenizing procedure of compost to produce sample CC results in the lowest mass loss (11.8\%, not including sieving). Successive acid and thermal treatments yielded to $44.9 \%$ and $67.9 \%$, to obtain C-SA and PC, respectively. A lower yield was obtained for PC-SA (30.2\%), due to the higher mass loss observed in the successive thermal and acid treatments $(69.8 \%$.) compared to C-SA and PC. The mass loss value of sample PC-SA-TE means that the mass was increased after the functionalization of the PC-SA sample with TEOS and EDTA. As observed, carbonization was achieved by pyrolysis of the sample, since the $\mathrm{C} / \mathrm{H}$ mass ratio of $\mathrm{C}$ (9.3) increased when pyrolyzed, obtaining sample PC (44.0). The decrease of the $\mathrm{C} / \mathrm{H}$ mass ratio from the PC sample to PC-SA $(\mathrm{C} / \mathrm{H}=37.2)$ and to PC-SA-TE $(\mathrm{C} / \mathrm{H}=27.4)$ is a consequence of the treatment with sulfuric acid $\left(\mathrm{H}_{2} \mathrm{SO}_{4}\right), \mathrm{TEOS}\left(\mathrm{SiC}_{8} \mathrm{H}_{20} \mathrm{O}_{4}\right)$ and EDTA $\left(\mathrm{C}_{10} \mathrm{H}_{16} \mathrm{~N}_{2} \mathrm{O}_{8}\right)$. The attack with sulfuric acid is evidenced by the leaching of inorganic material (ashes, $\mathrm{Ca}$, Fe, $\mathrm{Mg}$, Na decreases) and by the increment of the non-identified fraction, which may be associated to the oxygen content, in the samples C-SA and PC-SA prepared from CC and PC, respectively. The elemental composition of the samples was strongly affected, as observed in the S-content $(6.8 \%$ for C-SA and $8.1 \%$ for PC-SA samples, whereas $0.6 \%$ and $0.5 \%$ were found for $\mathrm{C}$ and PC samples, respectively) and in the metals content. The elemental composition of PC-SA-TE was also affected as a consequence of the functionalization with TEOS and EDTA that results in the incorporation of Si, C, H, N and O. However, the elemental composition was not affected as expected, since the total effective incorporation of $5 \mathrm{~mL}$ of TEOS and 0.1 $\mathrm{g}$ of EDTA should result theoretically in 19.9, 0.9, 7.7, 0.1, 66.6 and $4.8 \%$ of $\mathrm{C}, \mathrm{H}, \mathrm{S}, \mathrm{N}$, ashes and non-identified species, respectively. Thus, according to the mass balance, the efficiency on the incorporation of TEOS and EDTA is ca. $42 \%-51 \%$. The 


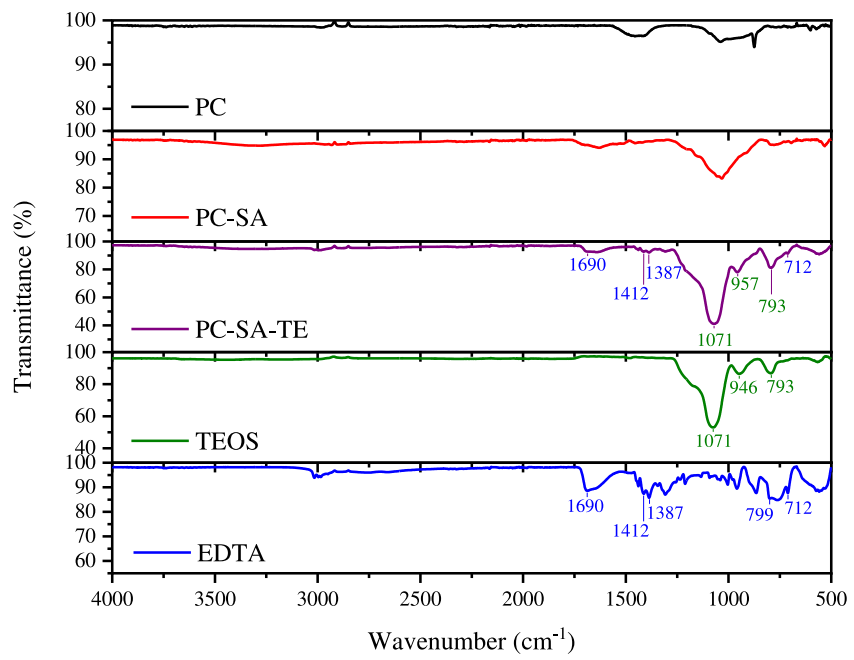

Fig. 1. FT-IR spectra of the PC, PC-SA and PC-SA-TE catalysts compared to the TEOS and EDTA spectra.

Table 1

Elemental analysis and remaining residua (ashes) of the materials, obtained by thermogravimetric analysis.

\begin{tabular}{|c|c|c|c|c|c|}
\hline Sample & CC & C-SA & PC & PC-SA & PC-SA-TE \\
\hline Mass loss (\%) & 11.8 & 55.1 & 42.1 & 69.8 & 40.9 \\
\hline $\mathrm{C}(\%)^{\mathrm{a}}$ & 21.3 & 20.1 & 17.6 & 18.6 & 19.2 \\
\hline $\mathrm{H}(\%)^{\mathrm{a}}$ & 2.3 & 1.7 & 0.4 & 0.5 & 0.7 \\
\hline $\mathrm{S}(\%)^{\mathrm{a}}$ & 0.6 & 6.8 & 0.5 & 8.1 & 7.8 \\
\hline $\mathrm{N}(\%)^{\mathrm{a}}$ & 1.7 & 1.0 & 0.0 & 0.0 & 0.2 \\
\hline $\mathrm{C} / \mathrm{H}$ & 9.3 & 11.8 & 44.0 & 37.2 & 27.4 \\
\hline Ashes (\%) & 55.5 & 34.3 & 81.5 & 69.2 & 67.9 \\
\hline $\mathrm{Ca}(\%)^{\mathrm{b}}$ & - & $<0.2$ & 9.35 & $<0.2$ & $<0.2$ \\
\hline $\mathrm{Al}(\%)^{\mathrm{b}}$ & - & 1.24 & 3.07 & 3.05 & 2.93 \\
\hline $\mathrm{Fe}(\%)^{\mathrm{b}}$ & - & $<0.2$ & 2.01 & 0.33 & 0.24 \\
\hline $\operatorname{Mg}(\%)^{b}$ & - & 0.2 & 1.76 & 0.42 & 0.37 \\
\hline $\mathrm{Na}(\%)^{\mathrm{b}}$ & - & $<0.1$ & 0.57 & 0.19 & 0.12 \\
\hline $\mathrm{Cu}(\%)^{\mathrm{b}}$ & - & $<0.1$ & $<0.1$ & $<0.1$ & $<0.1$ \\
\hline Non-identified $^{\mathrm{c}}(\%)$ & 18.6 & 41.0 & 0.0 & 3.6 & 4.2 \\
\hline
\end{tabular}

a Obtained by CHNS-elemental analyzer (maximum deviation for $\mathrm{C}$ of \pm 0.4 and lower than \pm 0.1 for other elements).

${ }^{b}$ Obtained by digestion of the catalyst and atomic absorption spectroscopy (maximum deviation of \pm 0.1 )

${ }^{\mathrm{c}}$ Non-identified composition is obtained by the subtraction of $\mathrm{C}, \mathrm{H}, \mathrm{S}, \mathrm{N}$ and ashes content from $100 \%$.

successful functionalization with TEOS and EDTA is evidenced by the FT-IR spectra of the catalysts (Fig. 1). The differences observed in the samples PC and PC-SA are due to the acid attack undergone by sample PC-SA that results in the leaching of metals and in the generation of surface oxygen and sulfur groups (Diaz de Tuesta et al., 2020c). The incorporation of TEOS on the sample PC-SA-TE is evident if the corresponding FT-IR spectra is compared to that of TEOS, since significant bands are observed at 1071, 946 and $793 \mathrm{~cm}^{-1}$, in line with other reports (Gui-Long et al., 2011; Wencel et al., 2013). The presence of EDTA is not so evident as the presence of TEOS, but some bands at 1690, 1412, 1387 and $712 \mathrm{~cm}^{-1}$ are observed in the FT-IR spectra of PC-SA-TE, similar to the FT-IR spectra of EDTA observed by other authors (Lin et al., 2011; Williams et al., 2019).

As a consequence of the calcination, acid treatment and EDTA-functionalization, the acidity and basicity of the samples changed. Acidity reached values of $1.03,1.66$ and $1.78 \mathrm{mmol} \mathrm{g}^{-1}$ for PC, PC-SA and PC-SA-TE samples, respectively; whereas 2.31, 1.45 and $1.55 \mathrm{mmol} \mathrm{g}^{-1}$ of basicity were found for PC, PC-SA and PC-SA-TE samples, respectively.

Fig. $\mathrm{S} 1$ shows the $\mathrm{N}_{2}$ adsorption-desorption isotherms of the samples PC-SA, PC-SA-TE, PC and C-SA. As observed, the samples prepared from compost are mainly non-porous or macroporous materials. The highest specific surface area was found for the sample PC $\left(S_{B E T}=91 \mathrm{~m}^{2} \mathrm{~g}^{-1}\right)$. The treatment of this sample with sulfuric acid (PC-SA) resulted in a decrease of the BET surface area $\left(41 \mathrm{~m}^{2} \mathrm{~g}^{-1}\right)$. The subsequent functionalization with TEOS and EDTA (PC-SA-TE) does not affect significantly the specific surface area $\left(S_{B E T}=38 \mathrm{~m}^{2} \mathrm{~g}^{-1}\right)$. 


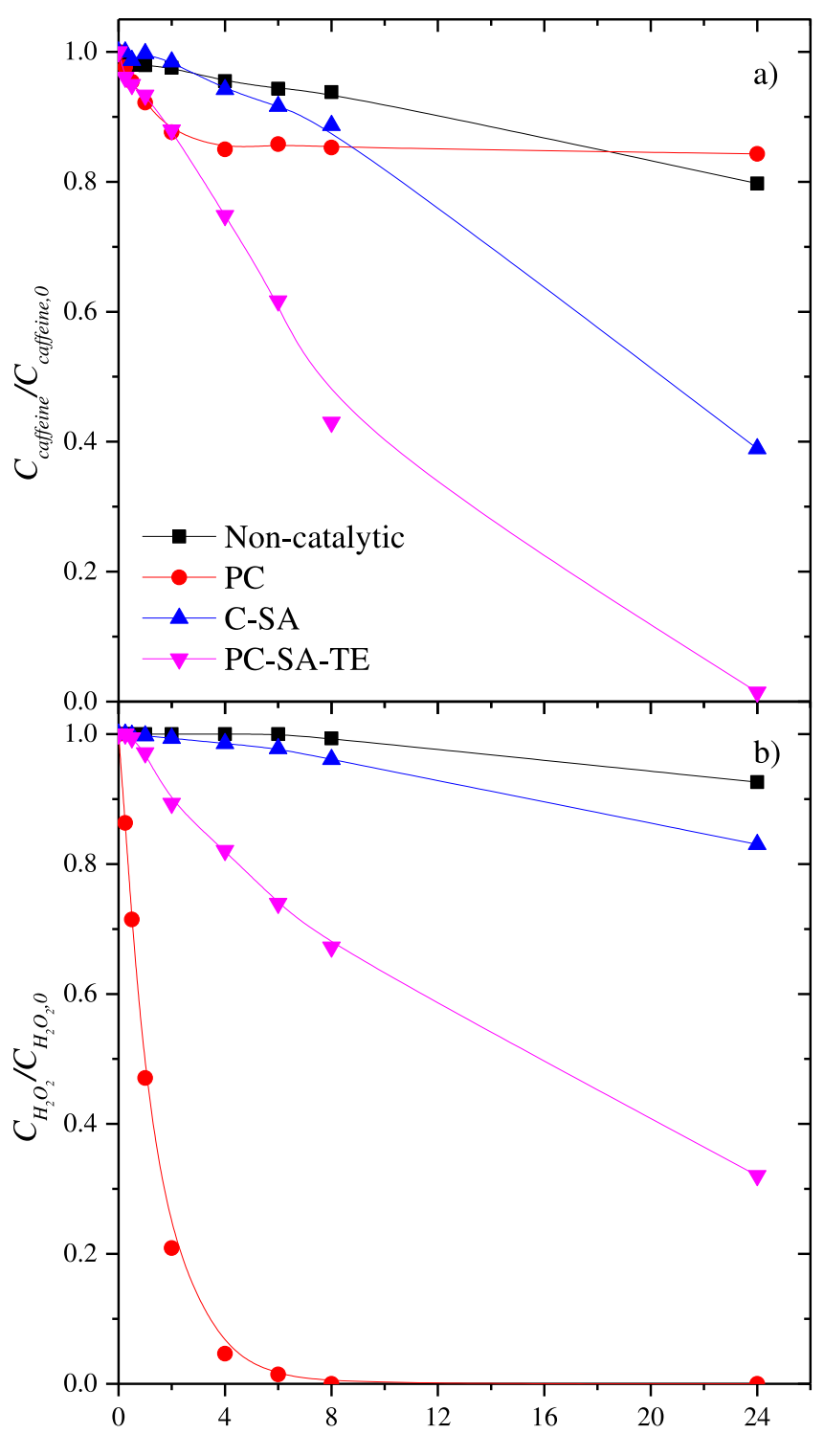

Time of reaction, $t(\mathrm{~h})$

Fig. 2. Evolution of concentration against time of (a) caffeine and (b) $\mathrm{H}_{2} \mathrm{O}_{2}$ in the wet peroxide oxidation of caffeine in catalytic and non-catalytic runs. Operating conditions: $353 \mathrm{~K}, \mathrm{pH}_{0}=3, \mathrm{C}_{\text {catal. }}=0.5 \mathrm{~g} \mathrm{~L}^{-1}, \mathrm{C}_{\text {caffeine, } 0}=0.515 \mathrm{mM}$ and stoichiometric quantity of $\mathrm{H}_{2} \mathrm{O}_{2}$ needed for the total mineralization of caffeine.

\subsection{Catalyst screening}

Fig. 2 shows the degradation of caffeine and the decomposition of hydrogen peroxide in the CWPO process with samples PC, C-SA and PC-SA-TE as catalysts. As observed, the sequential treatment of the pyrochar with $\mathrm{H}_{2} \mathrm{SO}_{4}$, TEOS and EDTA (PC-SA-TE) resulted in the material with the highest catalytic activity, $98.6 \%$ of caffeine being degraded; likely due to the highest acidity of this material. The pyrochar (PC), prior to the treatments with $\mathrm{H}_{2} \mathrm{SO}_{4}$, TEOS and EDTA, shows the lowest catalytic activity (the removal of caffeine reaches only $15.7 \%$ after $24 \mathrm{~h}$ ). Curiously, PC sample lead to obtain the highest conversion of hydrogen peroxide. The complete consumption of the oxidant after $8 \mathrm{~h}$ reveals that its decomposition is not effective for the degradation of caffeine, which is maintained constant from 4 to $24 \mathrm{~h}$, likely due to the fast consumption of $\mathrm{H}_{2} \mathrm{O}_{2}$ up to $4 \mathrm{~h}$ of reaction. The material resultant from the oxidation of the matured compost with sulfuric acid (C-SA) shows intermediate catalytic activity leading to obtain a caffeine conversion of $61.1 \%$ after $24 \mathrm{~h}$.

Klamerth et al. were able to obtain the complete removal of caffeine by photo-Fenton (homogeneous process) after

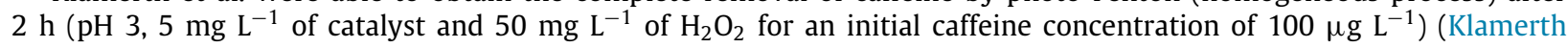




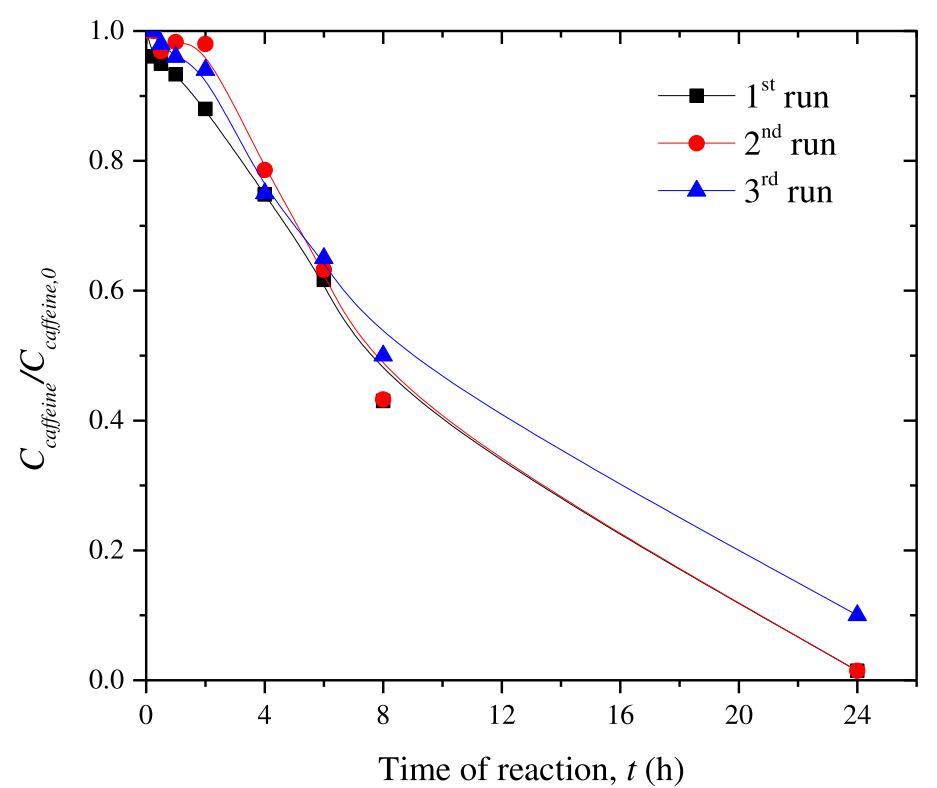

Fig. 3. Removal of caffeine by CWPO with catalyst PC-SA-TE used in three consecutive runs (Operating conditions: $353 \mathrm{~K}, \mathrm{H}_{0}=3, \mathrm{C}_{\text {catal. }}=0.5 \mathrm{~g} \mathrm{~L}^{-1}$, $C_{\text {caffeine }, 0}=0.515 \mathrm{mM}$ and stoichiometric quantity of $\mathrm{H}_{2} \mathrm{O}_{2}$ needed for the total mineralization of caffeine).

et al., 2010). However, the homogeneous process requires additional processing to recover the iron or to treat iron-sludge waste from the final effluents. When comparing the results obtained in this work with those of Motuzas et al. in which $98 \%$ removal of caffeine was achieved by CWPO with Fe into silicalite- 1 (mordenite framework inverted structure zeolite) after $24 \mathrm{~h}$ (at the conditions of $\mathrm{pH} 3,0.33 \mathrm{~g} \mathrm{~L}^{-1}$ of catalyst and $22 \mathrm{mM} \mathrm{H}_{2} \mathrm{O}_{2}$ for an initial caffeine concentration of $10 \mathrm{ppm}$ ) (Motuzas et al., 2018), it can be concluded that the catalysts developed in this work allow faster removal of the pollutant.

The leaching of some selected metals ( $\mathrm{Ca}, \mathrm{Al}, \mathrm{Fe}, \mathrm{Mg}, \mathrm{Na}, \mathrm{Cu}$ ) from catalyst was assessed by atomic absorption spectroscopy. No significant quantities was observed of any of those metals $\left(<0.1 \mathrm{mg} \mathrm{L}^{-1}\right)$ from the PC-SA and PC-SA-TE catalyst, while $\mathrm{Ca}\left(113 \mathrm{mg} \mathrm{L}^{-1}\right)$ and $\mathrm{Fe}\left(32 \mathrm{mg} \mathrm{L}^{-1}\right)$ were observed in the reaction media using PC catalyst ( $\mathrm{Al}, \mathrm{Mg}, \mathrm{Na}$, and $\mathrm{Cu}$ were not identified). Accordingly, $64 \%$ and $48 \%$ of Fe and Ca contained in PC sample were leached into the reaction media, but PC-SA and PC-SA-TE show stability due to the previous acid treatment of these catalysts.

\subsection{Study of stability and of operating conditions}

The stability of the EDTA-anchoring at the catalyst surface was assessed in a $\mathrm{H}_{2} \mathrm{O}_{2}$ decomposition run performed at the operating conditions previously considered ( $353 \mathrm{~K}, p H_{0}=3, C_{\text {catal. }}=0.5 \mathrm{~g} \mathrm{~L}^{-1}, C_{\text {caffeine }, 0}=0.515 \mathrm{mM}$ and the stoichiometric quantity of $\mathrm{H}_{2} \mathrm{O}_{2}$ needed for the total mineralization of caffeine) to observe the leaching of TEOS or EDTA by TOC analysis. The results obtained (TOC of the reaction medium $<0.2 \mathrm{mg} \mathrm{L}^{-1}$ ) evidenced the stability of the material PC-SA-TE. Additionally, the catalyst was used in three consecutive runs to assess its stability, as represented in Fig. 3. As observed, the removal of caffeine in the reaction runs conducted under the same operating conditions show similar values upon reaction time, confirming the stability of the catalyst prepared from matured compost and functionalized with TEOS and EDTA (PC-SA-TE).

The efficiency of caffeine removal with PC-SA-TE was further assessed at different temperatures (323-383 K) and catalyst concentrations $\left(0.125-2.5 \mathrm{~g} \mathrm{~L}^{-1}\right)$, as shown in Fig. 4. As observed, the highest conversion of caffeine $(>99.9 \%)$ and TOC removal (40.1\%) after $6 \mathrm{~h}$ were obtained at $383 \mathrm{~K}$ and $0.5 \mathrm{~g} \mathrm{~L}^{-1}$ of catalyst. The increase in the catalyst concentration from 0.5 to $2.5 \mathrm{~g} \mathrm{~L}^{-1}$ at $353 \mathrm{~K}$ allow to obtain higher conversions of caffeine (from 38.3 to $89.8 \%$ ) and removals of TOC (from 5.2 to $23.2 \%$ ). However, the contribution of the removal of caffeine by adsorption is more significant at high loads of catalyst, as observed in pure adsorption runs (removals of caffeine from 3 to $14 \%$ at concentrations of 0.5 and $2.5 \mathrm{~g} \mathrm{~L}^{-1}$ of PC-SA-TE, respectively).

\subsection{Kinetic insights on caffeine degradation}

The decrease of caffeine and hydrogen peroxide concentrations as function of time may be modeled by power-law kinetic equations of order 1 at the tested operating conditions (Fig. S2). As observed, the linear regression lead to obtain apparent kinetic constants $\left(k^{\prime}\right)$ for the degradation of caffeine between 0.03 and $4.34 \mathrm{~h}^{-1}$ (at the more severe conditions, 


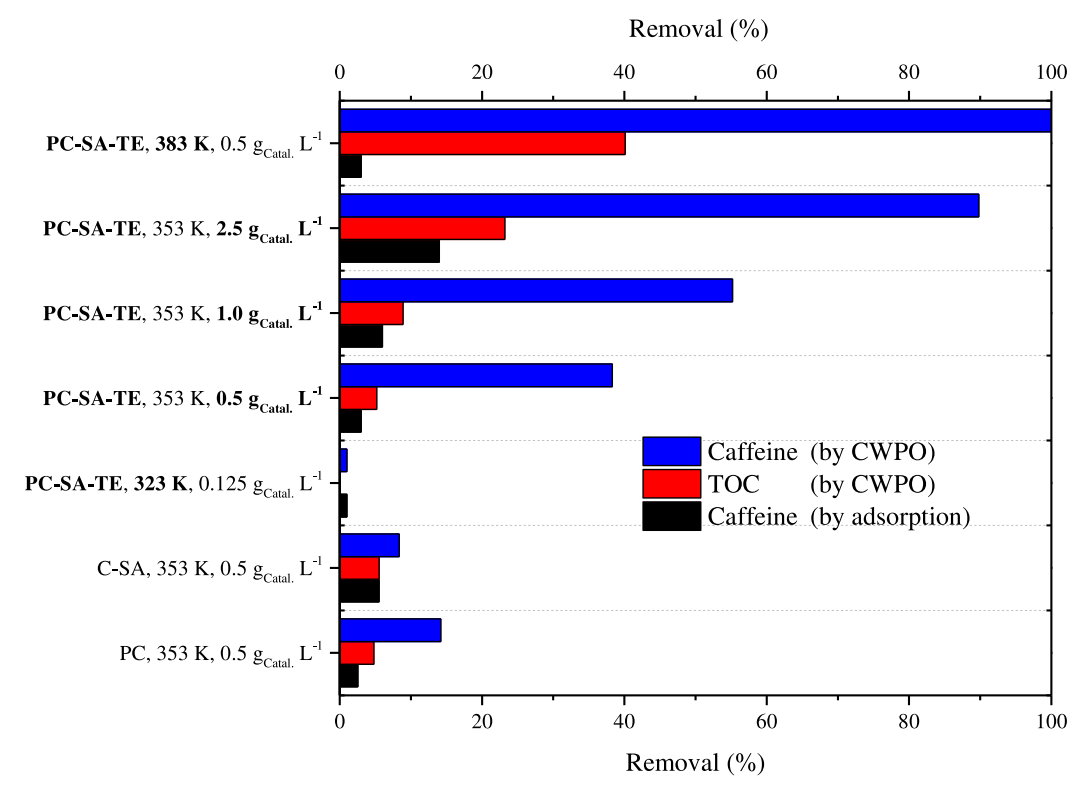

Fig. 4. Removal of caffeine and TOC by CWPO and by adsorption with sample PC-SA-TE after 6 h. Operating conditions: $p H_{0}=3, C_{\text {caffeine }, 0}=0.515$ $\mathrm{mM}$ and stoichiometric quantity of $\mathrm{H}_{2} \mathrm{O}_{2}$ needed for the total mineralization of caffeine.

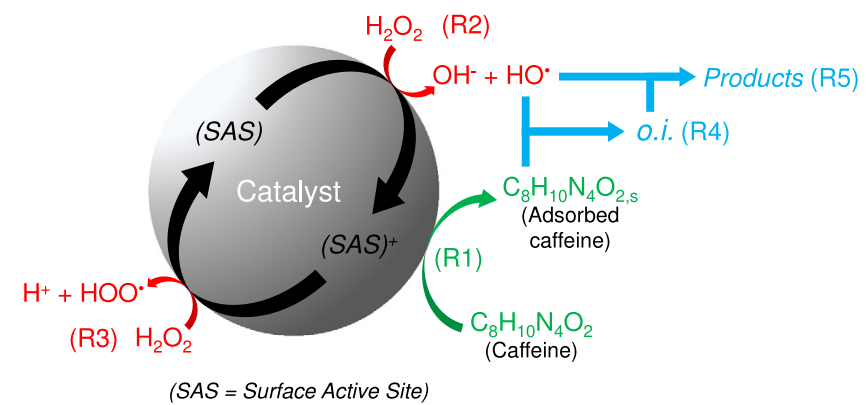

Fig. 5. Schematic representation of caffeine adsorption (R1), hydrogen peroxide reduction (R2) and oxidation (R3) at the catalyst surface; and oxidation of caffeine to oxidized intermediates, o.i., (R4) and of oxidized intermediates to final products (R5).

$383 \mathrm{~K}$ and $2.5 \mathrm{~g} \mathrm{~L}^{-1}$ of catalyst), whereas the apparent kinetic constants for $\mathrm{H}_{2} \mathrm{O}_{2}$ range from 0.02 to $0.46 \mathrm{~h}^{-1}$. Lower rate constants $\left(0.05-0.2 \mathrm{~h}^{-1}\right)$ were published previously for the degradation of caffeine by CWPO with Fe into silicalite- 1 catalysts (Motuzas et al., 2018).

For the peroxide oxidation with non-metal carbon-based catalysts, it is usually accepted that the decomposition of hydrogen peroxide occurs at active sites (surface functional groups able to exchange electrons) to produce hydroxyl and hydroperoxyl radicals $\left(\mathrm{HO}^{\bullet}\right.$ and $\mathrm{HOO}^{\bullet}$, respectively), which oxidize the organic matter adsorbed on the catalyst vicinity (Domínguez et al., 2013; Oliveira et al., 2004). The reaction rate of these radicals is higher than its diffusion rate in aqueous solutions $\left(2.10^{-5} \mathrm{~cm}^{2} \mathrm{~s}^{-1}\right)$ (Sun and Lemley, 2011), hence it may be considered that radicals oxidize the organic matter contained in wastewater only by reactions at the surface, as represented in Fig. 5. Therefore, it may be assumed that the degradation of caffeine occurs at the surface of the functionalized PC-SA-TE catalyst by the oxidation attack with the radicals produced from the decomposition of hydrogen peroxide (R1)-(R5).

$$
\begin{aligned}
& \mathrm{Caf}+\mathrm{S} \underset{k_{\text {des }}}{\stackrel{k_{\text {ads }}}{\rightleftarrows}} \mathrm{Caf} f_{s} \\
& \mathrm{H}_{2} \mathrm{O}_{2}+(S A S) \stackrel{{ }_{\mathrm{H}_{2} \mathrm{O}_{2}}}{\longrightarrow} \mathrm{OH}^{-}+\mathrm{HO}^{\bullet}+(S A S)^{+} \\
& \mathrm{H}_{2} \mathrm{O}_{2}+(S A S)^{+} \rightarrow \mathrm{H}^{+}+\mathrm{HOO}^{\bullet}+(S A S) \\
& \mathrm{Caf}_{s}+\mathrm{HO}^{\bullet} \stackrel{k_{0 x}}{\longrightarrow} 0 . i \text {. } \\
& \text { o.i. }+\mathrm{HO} \bullet \stackrel{k_{o x, o . i .}}{\longrightarrow} \text { Products }
\end{aligned}
$$


Accordingly, the kinetic equations for the adsorption of caffeine (R1) and for the decomposition of hydrogen peroxide (R2) may be expressed as Eqs. (5) and (6), respectively.

$$
\begin{aligned}
\frac{d C_{\text {caf }}}{d t} & =-k_{a d s} \cdot C_{\text {caf }} \cdot C_{\text {catal. }}+k_{\text {des }} \cdot C_{\text {caf }, s} \\
\frac{d C_{\mathrm{H}_{2} \mathrm{O}_{2}}}{d t} & =-k_{\mathrm{H}_{2} \mathrm{O}_{2}} \cdot C_{\mathrm{H}_{2} \mathrm{O}_{2}} \cdot C_{\text {catal. }}
\end{aligned}
$$

where $k_{a d s .}$ and $k_{\text {des. }}$ are the rate constants of the adsorption and desorption of caffeine, respectively, $k_{\mathrm{H}_{2} \mathrm{O}_{2}}$ is the rate constant of hydrogen peroxide decomposition; and $C_{c a f}, C_{c a f . s s}$ and $C_{\mathrm{H}_{2} \mathrm{O}_{2}}$ are the concentrations of caffeine in the bulk of the liquid, caffeine at the surface of the catalyst and of hydrogen peroxide, respectively. The kinetic equation of the caffeine concentration at the surface may be expressed as in Eq. (7).

$$
\frac{d C_{c a f, s}}{d t}=k_{a d s} \cdot C_{c a f} \cdot C_{c a t a l}-k_{d e s} \cdot C_{c a f, s}-k_{o x} \cdot C_{c a f, s} \cdot C_{\mathrm{HO}} \cdot
$$

where $k_{o x}$ is the kinetic rate constant of the reaction between caffeine and hydroxyl radicals (R4).

Assuming the steady-state caffeine concentration at the surface $\left(r_{c a f ., s}=0 \mathrm{mM} \mathrm{h}^{-1}\right)$, Eq. (8) is obtained.

$$
C_{\text {caf }, s}=\frac{k_{a d s} \cdot C_{c a f} \cdot C_{c a t a l}}{k_{\text {des }}+k_{o x} \cdot C_{\mathrm{HO}}}
$$

Eq. (8) can then be inserted into Eq. (7) to obtain Eq. (9).

$$
\frac{d C_{c a f}}{d t}=-k_{a d s} \cdot C_{c a f} \cdot C_{c a t a l}\left(\frac{1}{\frac{k_{d e s}}{k_{o x} \cdot C_{\mathrm{HO}}}+1}\right)
$$

Accordingly, the degradation of caffeine is directly proportional to its rate constant of adsorption on PC-SA-TE and to the concentration of caffeine and of catalyst. Furthermore, the rate of disappearance of caffeine depends on its desorption rate from the catalyst $\left(k_{d e s}\right)$ and on its oxidation with hydroxyl radicals $\left(k_{o x} \cdot C_{\mathrm{HO}} \cdot\right)$. On one hand, when the desorption rate of caffeine from the catalyst is considerably higher than the oxidation rate $\left(k_{\text {des }} \ggg k_{o x} \cdot C_{\mathrm{HO}}\right)$, the oxidation may not occur $\left(1 /\left(k_{\text {des }} / k_{0 \mathrm{x}} \cdot \mathrm{C}_{\mathrm{HO}}+1\right) \approx 0\right)$, since caffeine is desorbed prior to oxidize. On the other hand, when the desorption rate is much lower than the oxidation rate $\left(k_{\text {des }} \lll k_{o x} \cdot C_{\mathrm{HO}}\right)$, the rate of disappearance of caffeine is controlled by its adsorption at the surface of PC-SA-TE $\left(1 /\left(k_{\text {des }} / k_{o x} \cdot C_{\mathrm{HO}}\right) \approx 0\right)$.

The kinetic equation for the evolution of hydroxyl radicals concentration may be expressed taking into account its production from the decomposition of hydrogen peroxide (R2) and its consumption to oxidize caffeine (R4) and oxidized intermediates (R5)), as given in Eq. (10).

$$
\frac{d C_{\mathrm{HO}^{\bullet}}}{d t}=k_{\mathrm{H}_{2} \mathrm{O}_{2}} \cdot C_{\mathrm{H}_{2} \mathrm{O}_{2}} \cdot C_{\text {catal }}-k_{o x} \cdot C_{\text {caf }, s} \cdot C_{\mathrm{HO}} \cdot-\sum_{\text {o.i. }}^{p d t s} k_{o x, o . i .} \cdot C_{o . i ., s} \cdot C_{\mathrm{HO}} \cdot
$$

As the consumption of hydroxyl radicals is faster (high oxidation potential) than its production, typically it is considered the steady-state of hydroxyl radicals concentration $\left(r_{\mathrm{HO}} \cdot=0 \mathrm{mM} \mathrm{h}^{-1}\right)$ (Sun and Lemley, 2011), obtaining Eq. (11).

$$
C_{\mathrm{HO}} \cdot=\frac{k_{\mathrm{H}_{2} \mathrm{O}_{2}} \cdot C_{\mathrm{H}_{2} \mathrm{O}_{2}} \cdot C_{\text {catal }}}{k_{o x} \cdot C_{\text {caf }, s}+\sum_{\text {o.i. }}^{\text {pdts }} k_{o x, o . i .} \cdot C_{o . i ., s}}
$$

Therefore, the presence of hydroxyl radicals depends on the decomposition rate of hydrogen peroxide and its immediate consumption for the oxidation of caffeine and their oxidized intermediates.

If Eq. (11) is substituted into Eq. (9), Eq (12) is obtained.

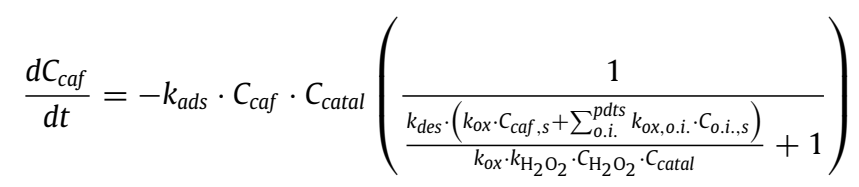

At an equimolar consumption rate of the organic matter (caffeine $+o . i$.) contained in the reaction media and of hydrogen peroxide, it is expected that the sum of the organic compounds per molar concentration of hydrogen peroxide would be approximately constant along the reaction (at least, until refractory compounds are obtained), as expressed in Eq. (13):

$$
\frac{C_{c a f, s}+\sum_{o . i .}^{p d t s} C_{o . i ., s}}{C_{\mathrm{H}_{2} \mathrm{O}_{2}}} \simeq \text { constant }
$$

Accordingly, the degradation of caffeine should be modeled by a pseudo-first power-law kinetic model, whenever its constant oxidation rate would be similar to the constant oxidation rate of the oxidized intermediates $\left(k_{o x} \simeq k_{o x, o . i .}\right)$, as given by Eq. (14).

$$
\frac{d C_{\text {caf }}}{d t} \simeq-k_{\text {caf }} \cdot C_{\text {caf }} \cdot C_{\text {catal }}
$$




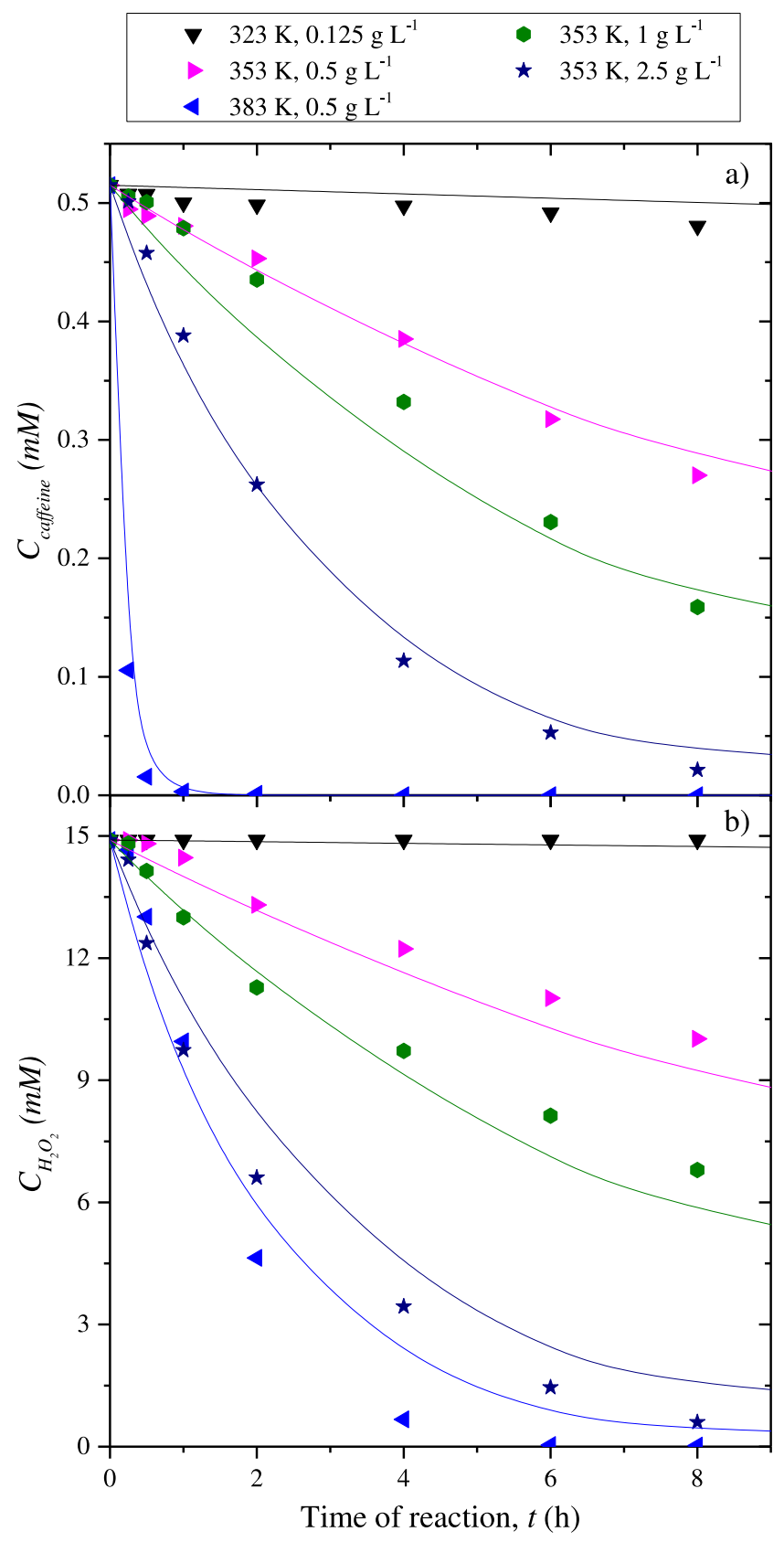

Fig. 6. Evolution of concentration against time of (a) caffeine and (b) $\mathrm{H}_{2} \mathrm{O}_{2}$ in the CWPO of caffeine with PC-SA-TE at different temperatures and quantities of catalyst. Operating conditions: $\mathrm{pH}_{0}=3, \mathrm{C}_{\text {caffeine }, 0}=0.515 \mathrm{mM}$ and stoichiometric quantity of $\mathrm{H}_{2} \mathrm{O}_{2}$ needed for the total mineralization of caffeine.

Accordingly, degradation of caffeine and consumption of hydrogen peroxide may be modeled by pseudo-first power-law models (Eq.'s (6) and (14)), as supported by Fig. S2. The fitting results considering the Arrhenius equation are summarized in Table 2. As observed, the rate constant for the degradation of caffeine take values in a wide range from $7.0 \cdot 10^{-4}$ to 13 $\mathrm{L} \mathrm{g}^{-1} \mathrm{~h}^{-1}$ when compared to the rate constant of hydrogen peroxide $\left(1.1 \cdot 10^{-2}-0.99 \mathrm{~L} \mathrm{~g}^{-1} \mathrm{~h}^{-1}\right)$. This may ascribed to the highest effect of temperature in the degradation of caffeine, as evidenced by the value of the activation energy ( $E a=169$ $\left.\mathrm{kJ} \mathrm{mol}^{-1}\right)$. In a previous study related with the CWPO of 4-nitrophenol, similar values of activation energy were obtained (102 and $103 \mathrm{~kJ} \mathrm{~mol}^{-1}$ for the constant rate of 4-nitrophenol and hydrogen peroxide disappearances, respectively) (Diaz de Tuesta et al., 2020b).

The fitness of caffeine degradation and hydrogen peroxide rate equations (Eqs. (6) and (14)) was found suitable according to the SEE and $\mathrm{R}^{2}$ values and their representation in Fig. 6 . 
Table 2

Kinetic model for the CWPO of caffeine with the catalyst PC-SA-TE.

\begin{tabular}{lllll}
\hline Model & $k^{323--383 K}\left(\mathrm{~L} \mathrm{~g}^{-1} \mathrm{~h}^{-1}\right)$ & $k_{0}\left(\mathrm{~L} \mathrm{~g}^{-1} \mathrm{~h}^{-1}\right)$ & $E a\left(\mathrm{~kJ} \mathrm{~mol}^{-1}\right)$ & $S E E$ \\
\hline$\frac{d \mathrm{C}_{\text {caf }}}{d t}=-k_{\text {caf }} \cdot C_{\text {caf }} \cdot C_{\text {catal. }}$ & $7.0 \cdot 10^{-4}-13$ & $(1.3 \pm 0.1) \cdot 10^{24}$ & $169 \pm 3$ & 0.064 \\
$\frac{d \mathrm{C}_{2} \mathrm{O}_{2}}{d t}=-k_{\mathrm{H}_{2} \mathrm{O}_{2}} \cdot C_{\mathrm{H}_{2} \mathrm{O}_{2}} \cdot C_{\text {catal. }}$ & $1.1 \cdot 10^{-2}-0.99$ & $(3.9 \pm 0.2) \cdot 10^{10}$ & $78 \pm 4$ & 0.988 \\
\hline
\end{tabular}

\section{Conclusions}

In this work it was demonstrated the suitability to prepare catalysts from matured compost obtained from mechanical and biological units of municipal solid waste. The highest catalytic activity can be obtained upon sequential thermal (1073 $\mathrm{K}$ ) and sulfuric acid treatments and functionalization with TEOS and EDTA. Furthermore, the catalysts prepared from the matured compost allows the complete removal of caffeine at low concentrations $(\leq 0.515 \mathrm{mM})$ by CWPO at $353-383 \mathrm{~K}$ and catalyst loads of $0.5-2.5 \mathrm{~g} \mathrm{~L}^{-1}$, after $6 \mathrm{~h}(1 \mathrm{~h}$ at $383 \mathrm{~K})$. Under these operating conditions caffeine degradation and hydrogen peroxide consumption can be modeled by pseudo-first power-law rate equations.

\section{CRediT authorship contribution statement}

Jose L. Diaz de Tuesta: Investigation, Conceptualization, Methodology, Formal analysis, Writing - original draft, Visualization. Flávio V.M. de Almeida: Investigation, Methodology. Jessica R.P. Oliveira: Investigation, Methodology. Paulo Praça: Funding acquisition, Project administration. Mário C. Guerreiro: Supervision. Helder T. Gomes: Supervision, Conceptualization, Writing - review \& editing, Funding acquisition, Project administration.

\section{Declaration of competing interest}

The authors declare that they have no known competing financial interests or personal relationships that could have appeared to influence the work reported in this paper.

\section{Acknowledgments}

This work was financially supported by project "VALORCOMP - Valorización de compost y otros desechos procedentes de la fracción orgánica de los residuos municipales", 0119_VALORCOMP_2_P, through FEDER under Program INTERREG; and CIMO (UIDB/00690/2020) through FEDER under Program PT2020.

\section{References}

Álvarez, S., et al., 2015. Synthesis of carbon xerogels and their application in adsorption studies of caffeine and diclofenac as emerging contaminants. Chem. Eng. Res. Des. 95, 229-238. http://dx.doi.org/10.1016/j.cherd.2014.11.001.

Álvarez Torrellas, S., et al., 2015. Chemical-activated carbons from peach stones for the adsorption of emerging contaminants in aqueous solutions Chem. Eng. J. 279, 788-798. http://dx.doi.org/10.1016/j.cej.2015.05.104.

Alvarez-Torrellas, S., et al., 2016. Removal of caffeine from pharmaceutical wastewater by adsorption: influence of NOM, textural and chemical properties of the adsorbent. Environ. Technol. 37, 1618-1630. http://dx.doi.org/10.1080/09593330.2015.1122666.

Anis, M., Haydar, S., 2018. Heterogeneous fenton oxidation of caffeine using zeolite-supported iron nanoparticles. Arab. J. Sci. Eng. 44, 315-328. http://dx.doi.org/10.1007/s13369-018-3659-3.

Cardoso, J., Gomes, H., Brito, P., 2019. Viability of the use of leachates from a mechanical biological municipal solid waste treatment plant as fertilizers. Recycling 4, e8. http://dx.doi.org/10.3390/recycling4010008.

Cheng, M., et al., 2017. Salicylic acid-methanol modified steel converter slag as heterogeneous fenton-like catalyst for enhanced degradation of alachlor. Chem. Eng. J. 327, 686-693. http://dx.doi.org/10.1016/j.cej.2017.06.153.

Chtourou, M., et al., 2018. Triclosan, carbamazepine and caffeine removal by activated sludge system focusing on membrane bioreactor. Process. Saf. Environ. Prot. 118, 1-9. http://dx.doi.org/10.1016/j.psep.2018.06.019.

Diaz de Tuesta, J.L., et al., 2020a. Catalysts prepared with matured compost derived from mechanical-biological treatment plants for the wet peroxide oxidation of pollutants with different lipophilicity. Catalysts 10 (1243), http://dx.doi.org/10.3390/catal10111243.

Diaz de Tuesta, J.L., et al., 2020b. The pH effect on the kinetics of 4-nitrophenol removal by CWPO with doped carbon black catalysts. Catal. Today 356, 216-225. http://dx.doi.org/10.1016/j.cattod.2019.08.033.

Diaz de Tuesta, J.L., et al., 2020c. Adsorption of sudan-IV contained in oily wastewater on lipophilic activated carbons: kinetic and isotherm modelling. Environ. Sci. Pollut. Res. 27, 20770-20785. http://dx.doi.org/10.1007/s11356-020-08473-1.

Diaz de Tuesta, J.L., et al., 2021. Assisted hydrothermal carbonization of agroindustrial byproducts as effective step in the production of activated carbon catalysts for wet peroxide oxidation of micro-pollutants. J. Environ. Chem. Eng. 9, 105004. http://dx.doi.org/10.1016/j.jece.2020.105004.

Domínguez, C.M., et al., 2013. The use of cyclic voltammetry to assess the activity of carbon materials for hydrogen peroxide decomposition. Carbon 60, 76-83. http://dx.doi.org/10.1016/j.carbon.2013.03.058.

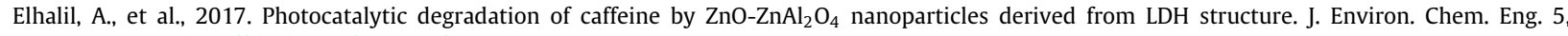
3719-3726. http://dx.doi.org/10.1016/j.jece.2017.07.037.

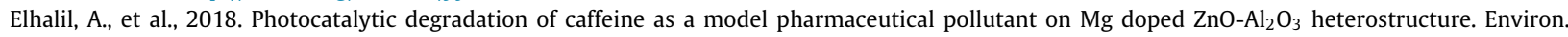
Nanotechnol. Monit. Manag. 10, 63-72. http://dx.doi.org/10.1016/j.enmm.2018.02.002. 
Eurostat, 2021. Municipal waste statistics - Statistics Explained (Data extracted in 2021). Eurostat https://ec.europa.eu/eurostat/statistics-explained/ index.php?title=Municipal_waste_statistics\#Municipal_waste_treatment (Accessed January 2021 2021).

Froehner, S., et al., 2010. Removal capacity of caffeine, hormones, and bisphenol by aerobic and anaerobic sewage treatment. Water Air Soil Pollut 216, 463-471. http://dx.doi.org/10.1007/s11270-010-0545-3.

Gui-Long, X., et al., 2011. Preparation and characterization of raspberry-like $\mathrm{SiO}_{2}$ particles by the sol-gel method. Nanomater. Nanotechnol. 1, 79-83. http://dx.doi.org/10.5772/45813.

Huaccallo, Y., et al., 2019. Magnetic $\mathrm{Fe}_{3} \mathrm{O}_{4} /$ multi-walled carbon nanotubes materials for a highly efficient depletion of diclofenac by catalytic wet peroxideoxidation. Environ. Sci. Pollut. Res. Int. 26, 22372-22388. http://dx.doi.org/10.1007/s11356-019-05597-x.

Huaccallo-Aguilar, Y., et al., 2021. New insights on the removal of diclofenac and ibuprofen by CWPO using a magnetite-based catalyst in an up-flow fixed-bed reactor. J. Environ. Manage. 281, 111913. http://dx.doi.org/10.1016/j.jenvman.2020.111913.

Juhola, R., et al., 2019. Biomass-based composite catalysts for catalytic wet peroxide oxidation of bisphenol A: Preparation and characterization studies. J. Environ. Chem. Eng. 7, 103127. http://dx.doi.org/10.1016/j.jece.2019.103127.

Keerthanan, S., et al., 2020. Engineered tea-waste biochar for the removal of caffeine, a model compound in pharmaceuticals and personal care products (PPCPs), from aqueous media. Environ. Tech. Innov. 19, 100847. http://dx.doi.org/10.1016/j.eti.2020.100847.

Kim, G., Choi, W., 2010. Charge-transfer surface complex of EDTA-TiO ${ }_{2}$ and its effect on photocatalysis under visible light. Appl. Catal. B 100, 77-83. http://dx.doi.org/10.1016/j.apcatb.2010.07.014.

Klamerth, N., et al., 2010. Application of photo-fenton as a tertiary treatment of emerging contaminants in municipal wastewater. Environ. Sci. Technol. 44, 1792-1798. http://dx.doi.org/10.1021/es903455p.

Korekar, G., Kumar, A., Ugale, C., 2020. Occurrence, fate, persistence and remediation of caffeine: a review. Environ. Sci. Pollut. Res. Int. 27, 34715-34733. http://dx.doi.org/10.1007/s11356-019-06998-8.

Lin, Y., et al., 2011. Preparation and characterization of core/shell-type Ag/Chitosan nanoparticles with antibacterial activity. Bull. Korean Chem. Soc. 32, 1277-1281. http://dx.doi.org/10.5012/bkcs.2011.32.4.1277.

Lu, M., et al., 2010. Removal of residual contaminants in petroleum-contaminated soil by fenton-like oxidation. J. Hazard. Mater. 179, 604-611 http://dx.doi.org/10.1016/j.jhazmat.2010.03.046.

Lv, D., et al., 2018. Application of EDTA-functionalized bamboo activated carbon (BAC) for $\mathrm{Pb}(\mathrm{II})$ and $\mathrm{Cu}(\mathrm{II})$ removal from aqueous solutions. Appl. Surf. Sci. 428, 648-658. http://dx.doi.org/10.1016/j.apsusc.2017.09.151.

Martin-Martínez, M., et al., 2016. Role of nitrogen doping on the performance of carbon nanotube catalysts: A catalytic wet peroxide oxidation application. ChemCatChem 8, 2068-2078. http://dx.doi.org/10.1002/cctc.201600123.

Messele, S.A., et al., 2019. Enhanced degradation of phenol by a fenton-like system $\left(\mathrm{Fe} / \mathrm{EDTA} / \mathrm{H}_{2} \mathrm{O}_{2}\right)$ at circumneutral pH. Catalysts 9 (474), http://dx.doi.org/10.3390/catal9050474.

Mirzaei, A., et al., 2017. Removal of pharmaceuticals from water by homo/heterogonous fenton-type processes - A review. Chemosphere 174, 665-688 http://dx.doi.org/10.1016/j.chemosphere.2017.02.019.

Mori, K., et al., 2012. Intercalation of Pt(II) terpyridine complexes into layered $K_{4} \mathrm{Nb}_{6} \mathrm{O}_{17}$ and visible-light-driven photocatalytic production of $H_{2}$. J. Phys. Chem. C 116, 18873-18877. http://dx.doi.org/10.1021/jp3059799.

Motuzas, J., et al., 2018. Environmental mineralization of caffeine micro-pollutant by Fe-MFI zeolites. Environ. Sci. Pollut. Res. Int. 25, 3628-3635. http://dx.doi.org/10.1007/s11356-017-0530-0.

Munoz, M., et al., 2017. Application of CWPO to the treatment of pharmaceutical emerging pollutants in different water matrices with a ferromagnetic catalyst. J. Hazard. Mater. 331, 45-54. http://dx.doi.org/10.1016/j.jhazmat.2017.02.017.

Ojajuni, O., et al., 2016. Rejection of caffeine and carbamazepine by surface-coated PVDF hollow-fiber membrane system. Ind. Eng. Chem. Res. 55 2417-2425. http://dx.doi.org/10.1021/acs.iecr.5b04055.

Oliveira, L.C.A., et al., 2004. The effect of $\mathrm{H}_{2}$ treatment on the activity of activated carbon for the oxidation of organic contaminants in water and the $\mathrm{H}_{2} \mathrm{O}_{2}$ decomposition. Carbon 42, 2279-2284. http://dx.doi.org/10.1016/j.carbon.2004.05.003.

Oliveira, TDd, et al., 2014. Caffeine oxidation in water by fenton and fenton-like processes: Effects of inorganic anions and ecotoxicological evaluation on aquatic organisms. J. Braz. Chem. Soc. http://dx.doi.org/10.5935/0103-5053.20140237.

Paiga, P., et al., 2019. Assessment of 83 pharmaceuticals in WWTP influent and effluent samples by UHPLC-MS/MS: hourly variation. Sci. Total Environ. 648, 582-600. http://dx.doi.org/10.1016/j.scitotenv.2018.08.129.

Pastrana-Martínez, L.M., et al., 2013. $\mathrm{TiO}_{2}$, surface modified $\mathrm{TiO}_{2}$ and graphene oxide- $\mathrm{TiO}_{2}$ photocatalysts for degradation of water pollutants under near-UV/Vis and visible light. Chem. Eng. J. 224, 17-23. http://dx.doi.org/10.1016/j.cej.2012.11.040.

Quintanilla, A., et al., 2019. Condensation by-products in wet peroxide oxidation: Fouling or catalytic promotion? Part I. Evidences of an autocatalytic process. Catalysts 9 (516), http://dx.doi.org/10.3390/catal9060516.

Ramirez, H., et al., 2019. Synthesis of coal fly ash zeolite for the catalytic wet peroxide oxidation of orange II. Environ. Sci. Pollut. Res. Int. 26, 4277-4287. http://dx.doi.org/10.1007/s11356-018-3315-1.

Ribeiro, R.S., et al., 2013. The influence of structure and surface chemistry of carbon materials on the decomposition of hydrogen peroxide. Carbon 62, 97-108. http://dx.doi.org/10.1016/j.carbon.2013.06.001.

Richardson, S.D., Kimura, S.Y., 2017. Emerging environmental contaminants: Challenges facing our next generation and potential engineering solutions. Environ. Tech. Innov. 8, 40-56. http://dx.doi.org/10.1016/j.eti.2017.04.002.

Roman, F.F., et al., 2021. Hydrochars from compost derived from municipal solid waste: Production process optimization and catalytic applications J. Environ. Chem. Eng. 9, 104888. http://dx.doi.org/10.1016/j.jece.2020.104888.

Santos Silva, A., et al., 2019. Wet peroxide oxidation of paracetamol using acid activated and Fe/Co-pillared clay catalysts prepared from natural clays. Catalysts 9 (705), http://dx.doi.org/10.3390/catal9090705.

Sun, S-P., Lemley, A.T., 2011. P-Nitrophenol degradation by a heterogeneous fenton-like reaction on nano-magnetite: Process optimization, kinetics, and degradation pathways. J. Mol. Catal. A Chem. 349, 71-79. http://dx.doi.org/10.1016/j.molcata.2011.08.022.

Tachiev, G., Roth, J.A., Bowers, A.R., 2000. Kinetics of hydrogen peroxide decomposition with complexed and free iron catalysts. Int. J. Chem. Kinet. 32, 24-35. http://dx.doi.org/10.1002/(SICI)1097-4601200032:1\{|T1|textless\}24::AID-JCK4\{|T1|textgreater\}3.0.CO;2-A.

Trovo, A.G., et al., 2013. Degradation of caffeine by photo-fenton process: optimization of treatment conditions using experimental design. Chemosphere 90, 170-175. http://dx.doi.org/10.1016/j.chemosphere.2012.06.022.

Van, H.T., et al., 2020. Heterogeneous fenton oxidation of paracetamol in aqueous solution using iron slag as a catalyst: Degradation mechanisms and kinetics. Environ. Tech. Innov. 18, 100670. http://dx.doi.org/10.1016/j.eti.2020.100670.

Wang, Y., et al., 2020. Calcium-loaded municipal sludge-biochar as an efficient and stable catalyst for biodiesel production from vegetable oil. ACS Omega 5, 17471-17478. http://dx.doi.org/10.1021/acsomega.0c01970. 
Wencel, D., et al., 2013. Synthesis, tailoring and characterization of silica nanoparticles containing a highly stable ruthenium complex. Nanotechnology 24, 365705. http://dx.doi.org/10.1088/0957-4484/24/36/365705.

Williams, O., et al., 2019. Removal of copper from cattle footbath wastewater with layered double hydroxide adsorbents as a route to antimicrobial resistance mitigation on dairy farms. Sci. Total Environ. 655, 1139-1149. http://dx.doi.org/10.1016/j.scitotenv.2018.11.330.

Zhu, Y., et al., 2019. Strategies for enhancing the heterogeneous fenton catalytic reactivity: A review. Appl. Catal. B 255, 117739. http://dx.doi.org/ 10.1016/j.apcatb.2019.05.041. 